\title{
PKM Penerapan Inovasi Pembelajaran di Paud Pati Gumentar
}

\author{
Iin Maulina1, Gandha Sunaryo Putra ${ }^{2}$, Ufi Ruhama'3 ${ }^{3}$, Selviana $^{4}$, Linda Suwarni ${ }^{5}$ \\ ${ }^{1}$ Fakultas Keguruan dan Ilmu Pendidikan, Universitas Muhammadiyah Pontianak \\ 2,3,4,5Fakultas Ilmu Kesehatan Universitas Muhammadiyah Pontianak \\ email: iin.maulina@unmuhpnk.ac.id
}

\begin{abstract}
PAUD Pati Gumentar is PAUD which is located in the coastal area of Pasir Village, Mempawah Regency. This PAUD has many limitations, including the high school graduate teaching staffs, so the learning model implemented is still very limited and classical. Besides, the PAUD Teachers also have a lack of understanding in carrying out the 2013 Curriculum which should be implemented in PAUD throughout West Kalimantan. Apart from that, the educational buildings and media in PAUD are very limited so that children have less explored in developing their abilities. In the health sector, only a small number of health promotions in PAUD render many children do not understand the importance of a Clean and Healthy Life Behavior. The purpose of this service is to provide information about learning innovations and the implementation of PHBS in PAUD Pati Gumentar. The method of this activity is the socialization of the 2013 curriculum and conducting a set of training on early childhood learning models as well as the provision of Educational and Media Teaching Aids, Comics, and Washing Hand with Soap (CTPS) Exercises. The result of the activity was the implementation of training on PAUD learning models and the 2013 Curriculum with a $60 \%$ increase in knowledge with a p-value of 0.000. Moreover, the provision for PAUD Learning Model Modules, Educational Teaching Aids (APE), Washbasin Media, and CTPS Comics, as well as CTPS Exercise Video can be carried out at PAUD Pati Gumentar.
\end{abstract}

Keywords: PAUD Learning Model; 2013 Curriculum, PHBS (Clean and Healthy Behavior), CTPS.

\begin{abstract}
Abstrak
Paud Pati Gumentar adalah Paud yang terletak di daerah Pesisir di Desa Pasir Kabupaten Mempawah. Paud ini memiliki banyak keterbatasan, diantaranya tenaga pengajar yang hanya lulusan SMA, sehingga model pembelajaran yang dilaksanakan masih sangat terbatas dan klasik. Selain itu Guru PAUD juga kurang memahami pelaksanaan Kurikulum 2013 yang seharusnya dilaksanakan di PAUD seluruh Kalimantan Barat. Selain itu bangunan dan media edukasi di Paud ini sangat terbatas sehingga anak-anak menjadi terbatas dalam mengembangkan kemampuan dirinya. Di bidang kesehatan, jarangnya promosi kesehatan di Paud ini menyebabkan banyak anak tidak memahami pentingnya Perilaku Hidup Bersih dan Sehat. Tujuan dari pengabdian ini adalah untuk memberikan informasi mengenai inovasi-inovasi pembelajaran dan penerapan PHBS di PAUD Pati Gumentar. Metode kegiatan ini adalah dengan sosialisasi kurikulum 2013 dan pelatihan model model pembelajaran PAUD serta pemberian bantuan Alat Peraga Edukasi dan Media, Komik, dan Senam Cuci Tangan pakai Sabun (CTPS). Hasil dari kegiatan adalah terlaksananya pelatihan model-model pembelajaran PAUD dan Kurikulum 2013 dengan peningkatan pengetahuan sebesar 60\% dengan p value 0,000. Terlaksananya pemberian bantuan Modul Model Pembelajaran PAUD, Alat Peraga Edukasi (APE), Media Wastafel dan Komik CTPS (Cuci Tangan Pakai Sabun), serta Video Senam CTPS di KB PAUD Pati Gumentar.
\end{abstract}

Kata Kunci : Paud, Pati Gumentar, Kurikulum 2013, Perilaku Hidup Bersih dan Sehat

\section{PENDAHULUAN}

Pendidikan Anak Usia Dini (PAUD) adalah suatu upaya pembinaan yang ditujukan kepada anak sejak lahir sampai dengan usia enam tahun yang dilakukan melalui pemberian rangsangan pendidikan untuk membantu pertumbuhan dan perkembangan jasmani dan rohani agar 
anak memiliki kesiapan dalam memasuki pendidikan lebih lanjut.[1]

Dengan diberlakukannya UU No.20

Tahun 2003, PAUD menjadi bagian dari sistem pendidikan di Indonesia yang integral dan sistemik. PAUD diselenggarakan sebelum jenjang Pendidikan Dasar. PAUD dapat diselenggarakan melalui jalur pendidikan formal, non-formal atau informal. PAUD pada jalur pendidikan formal berbentuk Taman Kanak-kanak (TK), Raudatul Athfal (RA). PAUD pada jalur pendidikan non-formal berbentuk Kelompok Bermain (KB), Taman Penitipan Anak (TPA). [2]

PAUD bertujuan mengembangkan berbagai potensi anak sejak dini sebagai persiapan untuk hidup dan dapat menyesuaikan diri dengan lingkungannya.[3] PAUD Pati Gumentar adalah PAUD yang terletak di Desa Pasir Kabupaten Mempawah. PAUD ini dibangun atas swadaya masyarakat, sejak 7 tahun yang lalu. Namun PAUD ini memiliki banyak keterbatasan, diantaranya tenaga pengajar seadanya. Guru PAUD diambilkan dari lulusan SMA, atau S1 yang tidak sesuai dengan bidangnya. Hal ini menyebabkan model pembelajaran yang seharusnya di kembangkan di PAUD tidak terlaksana dengan optimal. Akibatnya model pembelajaran di PAUD Pati Gumentar selama ini hanya menerapkan model pembelajaran yang klasikal yaitu pola pembelajaran di mana dalam waktu yang sama, kegiatan dilakukan oleh seluruh anak sama dalam satu kelas. Model pembelajaran ini merupakan model pembelajaran yang paling awal digunakan di TK, dengan sarana pembelajaran yang pada umumnya sangat terbatas, serta kurang memperhatikan minat individu anak. Disisi lain bangunan PAUD Pati Gumentar sangat memprihatinkan dan fasilitas pembelajaran yang minim membuat proses kegiatan PAUD tidak dapat berjalan sebagaimana mestinya. Minimnya fasilitas dan kurangnya pengetahuan guru PAUD, membuat sisi pendidikan dan kesehatan anak-anak paud juga jarang diperhatikan. Hal ini terlihat dari perilaku anak PAUD yang jajan sembarangan, membuang sampah sembarangan, dan tidak mencuci tangan sebelum makan. Hal ini mengakibatkan anak didik di PAUD Pati Gumentar ini tidak jarang yang mengalami diare, kecacingan, dan lain-lain. Hal ini diperparah dengan jarangnya petugas kesehatan melakukan promosi kesehatan di PAUD tersebut. Padahal, anak-anak merupakan generasi penerus bangsa, sehingga tubuh yang sehat dan kuat mutlak dibutuhkan dari masa anak-anak. Selain itu anak-anak dapat menjadi agent of change di masyarakat, artinya dapat menjadi agen perubahan di masyarakat dengan memberikan contoh penerapan Perilaku Hidup Bersih dan Sehat baik di lingkungan keluarga, sekolah maupun masyarakat [4]. Penerapan PHBS sejak dini dapat menjadi prevensi primer terhadap penyakit berbasis lingkungan, seperti diare, disentri, kecacingan, dan Demam Berdarah Dengue (DBD).

Berdasarkan pemaparan di atas maka Diperlukan solusi dalam mengatasi permasalahan yang ada melalui konsep Inovasi Model Pembelajaran Dan Promosi Kesehatan Pada PAUD Pati Gumentar.

\section{METODE PENGABDIAN}

Metode yang digunakan dalam kegiatan pengabdian ini adalah pemberdayaan kelompok sasaran melalui pelatihan penerapan kurikulum 2013 serta model-model pembelajaran inovatif pada PAUD. Selain itu juga diadakan kegiatan sosialisasi Perilaku Hidup Bersih dan Sehat. Kegiatan ini dilaksanakan di Desa Sungai Bakau Kecil Kabupaten Mempawah. Waktu pelaksanaan kegiatan ini dilaksanakan pada Bulan Juni-Juli 2020. Adapun tahapan dalam kegiatan ini sebagai berikut :

1. Tahap Awal 
Pada Tahap ini dilakukan koordinasi dengan Pengelola dan Guru PAUD Pati Gumentar Desa Pasir.

2. Tahap Periapan Materi dan Media Tahap ini dilakukan persiapan materi materi pelatihan, meliputi materi Penerapan kurikulum 2013 pada PAUD, materi model-model pembelajaran pada PAUD. Selanjutnya persiapan media, diantaranya modul model-model pembelajaran PAUD, Alat Peraga Edukasi (APE), komik Cuci Tangan Pakai Sabun (CTPS) dan Media Wastafel

3. Tahap Pelaksanaan Kegiatan Kegiatan yang akan dilaksanakakan berupa sosialisasi kurikulum 2013 dan pelatihan model model pembelajaran PAUD serta pemberian bantuan Alat Peraga Edukasi dan Media, Komik, dan Senam Cuci Tangan pakai Sabun (CTPS).

4. Pengawalan dan Pemantauan Kegiatan. Kegiatan pengawalan dan pemantauan inovasi Inovasi Model Pembelajaran Dan Promosi Kesehatan Pada Paud Di Daerah Pesisir ini dilakukan selama kegiatan Program Kemitraan Masyarakat (PKM) ini berlangsung untuk mengevaluasi dari kegiatan pelatihan dan pendampingan yang sudah dilakukan.

5. Evaluasi.

Evaluasi pelaksanaan program dilakukan setelah semua program terlaksana semuanya, dan setelah selesainya kegiatan PKM dilaksanakan. Untuk keberlanjutan program, maka tim pelaksana bersama mahasiswa akan tetap melakukan komunikasi dan kunjungan lapangan untuk memastikan keberlanjutan program dari kelompok mitra untuk melihat pelaksanaan dan keberlanjutan setelah kegiatan PKM ini selesai dilaksanakan selama 6 bulan.

\section{HASIL DAN PEMBAHASAN}

1. Sosialisasi Kurikulum 2013 Pada Guru PAUD

Kegiatan sosisalisasi Kurikulum 2013 diikuti sebanyak 22 Guru PAUD. Guru PAUD ini berasal dari PAUD Pati Gumentar dan PAUD yang ada disekitar Kecamatan Mempawah Hilir. Narasumber pada kegiatan ini adalah Ibu Iin Maulina, M.Pd, yang merupakan Dosen PAUD Pada Prodi Pendidikan Anak Usia Dini Universitas Muhammadiyah Pontianak. Kegiatan ini diawali dengan pembagian pretest untuk mengukur pengetahuan awal guru PAUD mengenai kurikulum 2013. Diakhir kegiatan dilaksanakan Post test untuk mengetahui perubahan atau peningkatan pengetahuan setelah dilakukan kegiatan.

Tabel 1. Perbedaan Mean pengetahuan sebelum dan Sosialisasi Kurikum 2013

\begin{tabular}{|l|l|l|l|l|}
\hline \multicolumn{2}{|c|}{ Variabel } & Mean & $\begin{array}{l}\text { Standar } \\
\text { Deviasi }\end{array}$ & $p$ value \\
\hline \multirow{3}{*}{ Pengetahuan } & Sebelum & 6,53 & 1,904 & 0,035 \\
\cline { 2 - 4 } & Sesudah & 8,91 & 1,767 & \\
\hline
\end{tabular}

sumber : Data Primer, 2020

Berdasarkan tabel 1 diatas diketahui terjadinya peningkatan skor mean pengetahuan responden mengenai Penerapan Kurikulum 2013 di PAUD dengan peningkatan sebesar 2,38. Hasil uji $\mathrm{t}$ berpasangan diperoleh nilai $\mathrm{p}$ sebesar 0,035 (kurang dari 0,05), sehingga dapat disimpulkan bahwa peningkatan skor pengetahuan tersebut signifikan. Dengan kata lain, sosialisasi penerapan kurikulum 2013 pada PAUD Pati Gumentar efektif meningkatkan pengetahuan guru PAUD.
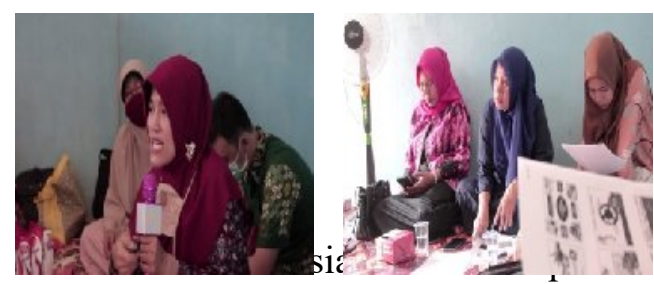

Kurikulum 2013 Pada PAUD Pati Gumentar 
2. Pelatihan Model-Model Pembelajaran PAUD

Kegiatan pelatihan model-model Pembelajaran PAUD diikuti oleh 22 Guru PAUD. Kegiatan ini diawali dengan pre test dan di akhiri dengna post test. Pelatihan ini disampaikan oleh Ibu Ufi Ruhama', M.Pd dosen dari Universitas Muhammadiyah Pontianak. Selain materi, peserta juga diberikan Modul model-model pembelajaran PAUD. Peserta dijelskan tentang cara menciptakan pembelajaran yang mengedepankan interaksi yang lebih luas, yaitu interaksi dan komunikasi yang dilakukan antara guru dengan siswa, siswa dengan siswa, dan siswa dengan guru.[5] Komunikasi atau dialog antara guru dengan anak sangatlah penting, dan benar-benar menjadi sarana untuk membantu anak berkembang, atau mengembangkan lencen hom don memikirkan car $\mathrm{k}$

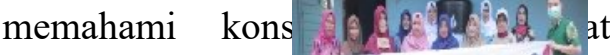

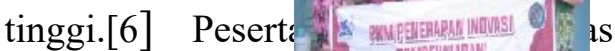
mengikuti pelatiha dari aktifnya $\mathrm{p}$ si diskusi. Pada se. ................. dt peserta menyampaikan kendalakendala mereka dalam mengembangkan inovasi pembelajaran PAUD yang selama ini hanya diterapkan dengan klasik. Narasumber menyampaikan solusi atas permasalahan tersebut dan juga mempraktekkan model-model yang dapat diterapkan pada PAUD Pati Gumentar. Dengan adanya praktek tersebut guru PAUD menjadi paham mengenai penerapan model-model pembelajaran PAUD yang telah disampaikan. Berikut hasil pengukuran pre dan post test mengenai pelatihan model-model pembelajaran PAUD.
Tabel 2. Perbedaan Mean pengetahuan sebelum dan sesudah Pelatihan ModelModel Pembelajaran PAUD

\begin{tabular}{|l|l|l|l|l|}
\hline \multicolumn{2}{|c|}{ Variabel } & Mean & $\begin{array}{l}\text { Standar } \\
\text { Deviasi }\end{array}$ & $p$ value \\
\hline \multirow{3}{*}{ Pengetahuan } & Sebelum & 8,58 & 1,974 & 0,00 \\
\cline { 2 - 4 } & Sesudah & 10,91 & 1,787 & \\
\hline
\end{tabular}

Berdasarkan tabel 1 diatas diketahui terjadinya peningkatan skor mean pengetahuan responden mengenai ModelModel Pembelajaran di PAUD dengan peningkatan sebesar 2,33. Hasil uji $t$ berpasangan diperoleh nilai $\mathrm{p}$ sebesar 0,000 (kurang dari 0,05), sehingga dapat disimpulkan bahwa peningkatan skor pengetahuan tersebut signifikan. Dengan kata lain, Pelatihan Mdodel-Model Pembelajaran pada PAUD Pati Gumentar efektif meningkatkan pengetahuan guru PAUD.

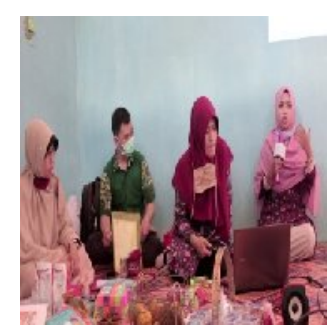

Gambar 2. Pelatihan Model-Model
Pembelajaran PAUD

3. Pemberian dan Serah Terima Bantuan Media

Setelah kegiatan sosialisasi dan pelatihan dilaksanakan, dilanjutkan dengan pemberian bantuan media Alat Peraga Edukasi, Modul Model Pembelajaran PAUD, Komik CTPS (Cuci Tangan pakai Sabun ), Video Senam CTPS dan Media Wastafel. Kegiatan ini diawali dengan pemaparan materi mengenai Pentingnya Penerapan PHBS, terutama Penerapan Protokol Kesehatan di Sekolah 
sehubungan dengan Pandemi Covid-19. Pamaparan disampaikan oleh narasumber yaitu bapak Gandha Sunaryo Putra, M, Kes. Setelah itu kegiatan dilanjutkan dengan penyerahan bantuan media kepada pengelola PAUD Pati Gumentar. Kegiatan ini diberikan langsung oleh Tim PKM kepada mitra yaitu Pihak PAUD Pati Gumentar yang di wakili oleh Kepala Sekolah yaitu ibu Suryati, S.Pd. Kegiatan ini dilanjukan dengan penandatanganan berita acara dan foto bersama. Ibu Suryati menyampaikan rasa terimakasih dan syukur atas terlaksananya kegiatan ini di PAUD Pati Gumentar. Transfer ilmu yang telah diberikan oleh tim PKM dari Universitas Muhammadiyah Pontianak sangat berguna dalam meningkatkan pengetahuan guru PAUD,selain itu Teknologi Tepat Guna yang diberikan sangat bermanfaat guna menunjang pembelajaran di PAUD dan dalam menjaga kesehatan anak-anak PAUD.

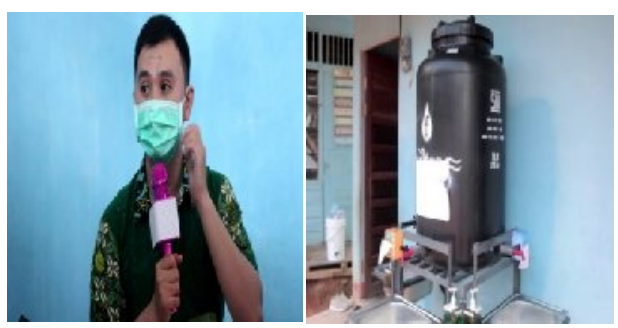

Gambar 3. Penjelasan Penerapan PHBS di Sekolah

\section{SIMPULAN}

Kegiatan PKM penerapan inovasi pembelajaran dan penerapan PHBS Di PAUD Pati Gumentar ini diharapkan dapat membantu meningkatkan pengetahuan Guru PAUD dalam menerapkan kurikulum 2013 dan memvariasikan model-model pembelajaran di PAUD agar lebih optimal dan menyenangkan. Selain itu kesehatan guru maupun anak-anak PAUD diharapkan dapat terjaga dengan baik guna meningkatkan optimalisasi kegiatan di PAUD.

\section{UCAPAN TERIMAKASIH}

Terimakasih kepada Ristek-Brin yang telah mendanai kegiatan ini dalam Hibah Program Kemitraan Masyarakat (PKM) Tahun 2020.

\section{DAFTAR PUSTAKA}

[1] UU No. 20 Tahun 2003. Sistem Pendidikan Nasional. Jakarta : Visimedia

[2] Rozalena \& Kristiawan, M. 2017. Pengelolaan Pembelajaran Paud Dalam Mengembangkan Potensi Anak Usia Dini. Jurnal Manajemen, Kepemimpinan, dan Supervisi Pendidikan. 2(1): 76-86

[3] Yuliani, N.2011. Konsep Dasar Pendidikan Anak Usia Dini. Jakarta: Indeks; 2011.

[4] Selviana, et al. 2018. Determinan Perilaku Hidup Bersih dan Sehat Pada Siswa SD Muhammadiyah 1 dan 3 Di Kota Pontianak. Jurnal Publikasi Kesehatan Masyarakat Indonesia. 5(2): 53-58

[5] Ibid., R. 2012. Model-Model Pembelajaran (Mengembangkan Profesionalisme Guru)., h. 203.

[6] Marisson, GS. 2012. Dasar-Dasar Pendidikan Anak Usia Dini (PAUD) . (Edisi Kelima), (Jakarta Barat, PT Indeks, 2012), h. 80 